The application of our previously reported idea to the three-phase distillation column is quite successful, thus presenting a powerful procedure. The present procedure has the simplicity of the boiling point type method as well as great stability in finding out rigorous solutions satisfying all the basic equations derived.

\begin{tabular}{|c|c|}
\hline \multicolumn{2}{|c|}{ Nomenclature } \\
\hline$F$ & $=$ flow rate of feed stream \\
\hline$H$ & $=$ molar enthalpy of vapor \\
\hline$H^{*}$ & $\begin{aligned} &= \text { molar enthalpy of vapor of pure } \\
& \text { component }\end{aligned}$ \\
\hline$H_{F}$ & $=$ molar enthalpy of feed \\
\hline$h$ & $=$ molar enthalpy of liquid \\
\hline$h^{*}$ & $\begin{aligned} &= \text { molar enthalpy of liquid of pure } \\
& \text { component }\end{aligned}$ \\
\hline$K$ & $=$ vapor-liquid equilibrium ratio \\
\hline$K^{+}$ & $=$liquid-liquid equilibrium ratio \\
\hline$L$ & $=$ flow rate of liquid stream \\
\hline $\bar{L}$ & $\begin{aligned}= & \text { overall flow rate of liquid stream } \\
& \text { defined by Eq. (4) }\end{aligned}$ \\
\hline$m$ & $=$ total number of components \\
\hline$N$ & $=$ number of total theoretical stages \\
\hline$R$ & $=$ reflux ratio \\
\hline
\end{tabular}

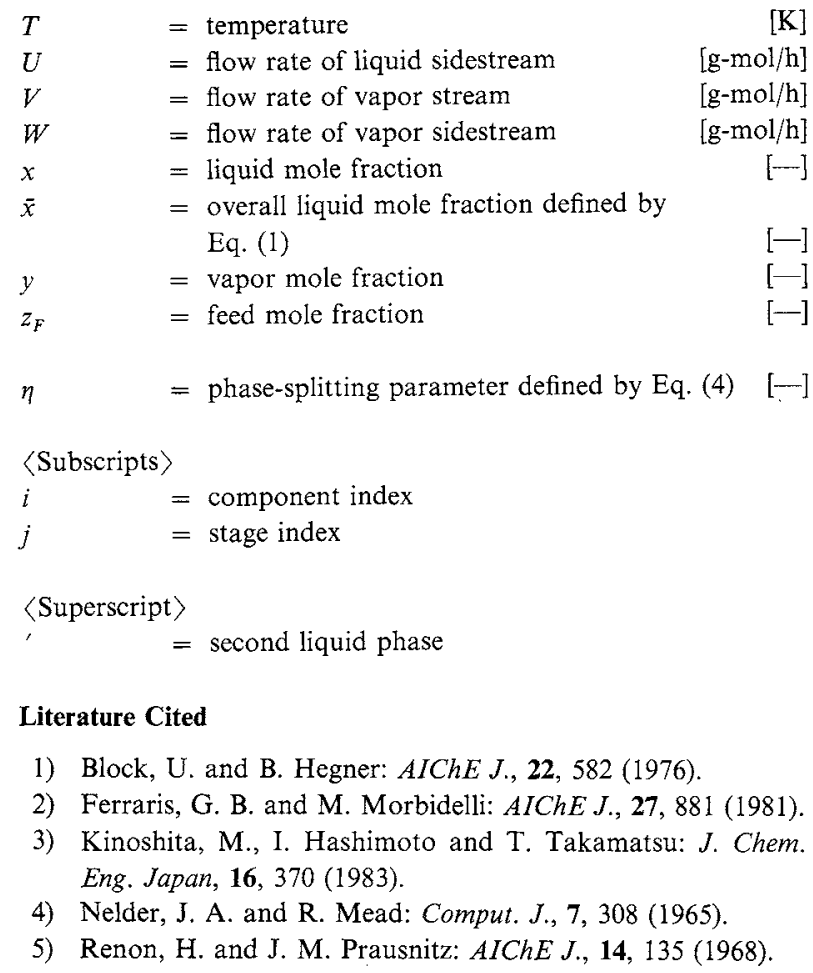

\title{
EFFECT OF CHLORINE HYDROLYSIS REACTION ON ABSORPTION OF CHLORINE INTO AQUEOUS SODIUM BICARBONATE SOLUTIONS
}

HARUO HIKITA, SATORU ASAI AND YASUHIRO KONISHI

Department of Chemical Engineering, University of Osaka Prefecture, Sakai 591

In a previous paper ${ }^{5)}$ the authors reported on the kinetics of the absorption of $\mathrm{Cl}_{2}$ into aqueous $\mathrm{NaHCO}_{3}$ solutions accompanied by the desorption of $\mathrm{CO}_{2}$ in a baffled agitated vessel operated batchwise. The measured absorption rates of $\mathrm{Cl}_{2}$ and the desorption rates of $\mathrm{CO}_{2}$ were in good agreement with the theoretical predictions from the chemical absorption theory based on the Lévêque model, which assumes no effect of the $\mathrm{Cl}_{2}$ hydrolysis reaction. For absorption into dilute $\mathrm{NaHCO}_{3}$ solutions, however, the $\mathrm{Cl}_{2}$ hydrolysis reaction may be considered to make an appreciable contribution to the absorption rate of $\mathrm{Cl}_{2}$. In the present work, absorption experiments were carried out in the same agitated vessel as in the previous work ${ }^{5)}$ using a very dilute $\mathrm{NaHCO}_{3}$ solution of $B_{f}=33.0 \mathrm{~mol} / \mathrm{m}^{3}$. The present experimen-

Received January 6, 1983. Correspondence concerning this article should be addressed. to H. Hikita. tal results and the previous data ${ }^{5)}$ obtained with $\mathrm{NaHCO}_{3}$ solutions of concentrations below $254 \mathrm{~mol} /$ $\mathrm{m}^{3}$ were analyzed by the chemical absorption theory which takes into account the effect of the $\mathrm{Cl}_{2}$ hydrolysis reaction.

\section{Chemical Absorption Mechanism}

When $\mathrm{Cl}_{2}$ is absorbed into aqueous $\mathrm{NaHCO}_{3}$ solutions, the following reactions may take place in the liquid phase:

$$
\begin{aligned}
& \mathrm{Cl}_{2}+\mathrm{HCO}_{3}^{-} \longrightarrow \mathrm{CO}_{2}+\mathrm{HOCl}+\mathrm{Cl}^{-} \\
& \mathrm{HOCl}+\mathrm{HCO}_{3}^{-} \rightleftharpoons \mathrm{CO}_{2}+\mathrm{OCl}^{-}+\mathrm{H}_{2} \mathrm{O} \\
& \mathrm{Cl}_{2}+\mathrm{OCl}^{-}+\mathrm{H}_{2} \mathrm{O} \longrightarrow 2 \mathrm{HOCl}+\mathrm{Cl}^{-} \\
& \mathrm{Cl}_{2}+\mathrm{H}_{2} \mathrm{O} \rightleftharpoons \mathrm{HOCl}+\mathrm{H}^{+}+\mathrm{Cl}^{-}
\end{aligned}
$$

Reactions (1) and (3) are instantaneous irreversible 
reactions and reactions (2) and (4) are reversible reactions of finite reaction rates, as discussed in the previous paper. ${ }^{5)}$ Therefore, the absorption of $\mathrm{Cl}_{2}$ into aqueous $\mathrm{NaHCO}_{3}$ solutions can be regarded as a process of absorption accompanied by two instantaneous irreversible reactions represented by reactions (1) and (3) and two reversible reactions of finite reaction rates represented by reactions (2) and (4).

According to the reaction scheme described above, the concentration profile of each species in the liquid phase will be similar to that shown in Fig. 1. In this case, reaction (4) may occur with a finite reaction rate in region 1 and reactions (1) and (3) and the following two reactions may take place irreversibly and instantaneously at the reaction plane.

$$
\begin{aligned}
& \mathrm{H}^{+}+\mathrm{HCO}_{3}^{-} \longrightarrow \mathrm{CO}_{2}+\mathrm{H}_{2} \mathrm{O} \\
& \mathrm{H}^{+}+\mathrm{OCl}^{-} \longrightarrow \mathrm{HOCl}
\end{aligned}
$$

(The equilibrium constants of reactions (5) and (6) are $2.25 \times 10^{3} \mathrm{~m}^{3} / \mathrm{mol}^{3)}$ and $3.44 \times 10^{4} \mathrm{~m}^{3} / \mathrm{mol}^{6)}$ at $25^{\circ} \mathrm{C}$ and infinite dilution; reaction (5) is very fast with a rate constant of $58.5 \mathrm{~m}^{3} / \mathrm{mol} \cdot \mathrm{s}^{7)}$ at $25^{\circ} \mathrm{C}$ and infinite dilution, and reaction (6) is a proton transfer reaction and may be regarded as instantaneous.) Further, in region 2 , reaction (2) will proceed reversibly at a finite reaction rate.

When $\mathrm{Cl}_{2}$ is absorbed into a concentrated $\mathrm{NaHCO}_{3}$ solution, the $\mathrm{Cl}_{2}$ hydrolysis reaction may be suppressed and will make a negligible contribution to the absorption rate of $\mathrm{Cl}_{2}$, since $\mathrm{HOCl}$ and $\mathrm{Cl}^{-}$ions of high concentrations are formed in region 1 . The concentration profile of each species in this case will be as shown in the previous paper. ${ }^{5)}$

The experimental results obtained in the present work were analyzed by using the chemical absorption theory based on the Lévêque model as in the previous papers. ${ }^{4,5)}$ For the present problem, an approximate analytical solution of the differential equations describing the diffusion of all species in the liquid phase was obtained by replacing the diffusivity ratios in the analytical solution based on the film model by the two-thirds roots. The absorption rate of $\mathrm{Cl}_{2}, N_{A}$, and the desorption rate of $\mathrm{CO}_{2}, N_{C}$, are given by

$$
N_{A}=\beta_{A} k_{L A} A_{i}
$$

and

$$
N_{C}=\beta_{C} k_{L C}\left(C_{r}-C_{i}\right)
$$

with

$$
\begin{gathered}
\beta_{A}=\frac{\gamma\left(1-\frac{E_{i} F_{i} J_{i}}{K_{4} A_{i}}\right)}{\tanh \left(\gamma / \beta_{C}\right)}+\frac{\frac{\gamma}{K_{4}}}{\sinh \left(\gamma / \beta_{C}\right)} \frac{E_{i} F_{i} J_{i}}{A_{i}} \\
\beta_{C}=\beta_{A} /\left[\beta_{A}-\left(\frac{D_{B}}{D_{A}}\right)^{2 / 3} \frac{B_{0}}{A_{i}}-\left(\frac{D_{G}}{D_{A}}\right)^{2 / 3} \frac{G_{0}}{A_{i}}\right]
\end{gathered}
$$

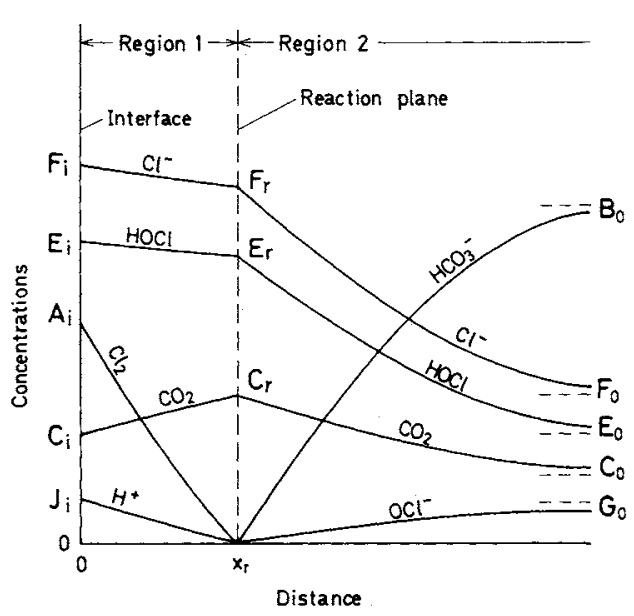

Fig. 1. Concentration profiles for absorption of $\mathrm{Cl}_{2}$ into aqueous $\mathrm{NaHCO}_{3}$ solution.

$$
\gamma=\sqrt{k_{4} D_{A}} / k_{L A}
$$

where $\beta_{A}$ and $\beta_{C}$ are the reaction factors for the absorption of $\mathrm{Cl}_{2}$ and the desorption of $\mathrm{CO}_{2}$, respectively. The concentration of $\mathrm{CO}_{2}$ at the reaction plane, $C_{r}$, is given by

$$
C_{r}=C_{i}+\frac{1}{\beta_{C}}\left[C_{0}-C_{i}+\left(\frac{D_{B}}{D_{C}}\right)^{2 / 3} B_{0}\right]
$$

Further, the concentrations of $\mathrm{HOCl}, \mathrm{Cl}^{-}$ions and $\mathrm{H}^{+}$ions, $E_{i}, F_{i}$ and $J_{i}$ respectively, are given by

$$
\begin{aligned}
& E_{i}=E_{0}+\left(\frac{D_{B}}{D_{E}}\right)^{2 / 3} B_{0}+2\left(\frac{D_{G}}{D_{E}}\right)^{2 / 3} G_{0}+\left(\frac{D_{J}}{D_{E}}\right)^{2 / 3} J_{i} \\
& F_{i}=F_{0}+\left(\frac{D_{B}}{D_{F 2}}\right)^{2 / 3} B_{0}+\left(\frac{D_{G}}{D_{F 2}}\right)^{2 / 3} G_{0}+\left(\frac{D_{J}}{D_{F 1}}\right)^{2 / 3} J_{i} \\
& J_{i}=\left(\beta_{A}-1\right)\left(\frac{D_{A}}{D_{J}}\right)^{2 / 3} A_{i}-\left(\frac{D_{B}}{D_{J}}\right)^{2 / 3} B_{0}-\left(\frac{D_{G}}{D_{J}}\right)^{2 / 3} G_{0}
\end{aligned}
$$

Substituting Eq. (12) into Eq. (8) gives the following expression for $N_{C}$ :

$$
N_{C}=k_{L C}\left[C_{0}-C_{i}+\left(\frac{D_{B}}{D_{C}}\right)^{2 / 3} B_{0}\right]
$$

This equation indicates that the desorption rate $N_{C}$ of $\mathrm{CO}_{2}$ is independent of the $\mathrm{Cl}_{2}$ hydrolysis reaction represented by reaction (4).

If the $\mathrm{Cl}_{2}$ hydrolysis reaction can be neglected, that is, when both $K_{4}$ and $k_{4}$ equal zero, Eqs. (9) and (10) lead to

$$
\beta_{A}=\beta_{C}=1+\left(\frac{D_{B}}{D_{A}}\right)^{2 / 3} \frac{B_{0}}{A_{i}}+\left(\frac{D_{G}}{D_{A}}\right)^{2 / 3} \frac{G_{0}}{A_{i}}
$$

and Eq. (15) reduces to

$$
J_{i}=0
$$

Equation (17) is identical to Eq. (19) given in the previous paper. ${ }^{5)}$ 


\section{Experimental}

The agitated vessel was of $12.3 \mathrm{~cm}$ i.d. and was the same as that used in the previous work. ${ }^{5}$ The experimental procedure was also similar to that employed in the previous work. ${ }^{5}$ The vessel was operated batchwise with respect to the liquid. Experiments were carried out at atmospheric pressure and at $25^{\circ} \mathrm{C}$. The absorbing liquid used was an aqueous $\mathrm{NaHCO}_{3}$ solution of an initial concentration of $33.0 \mathrm{~mol} / \mathrm{m}^{3}$. The gas phase was pure $\mathrm{Cl}_{2}$ saturated with water vapor, and its feed rate was maintained at approximately $1.6 \times 10^{-5} \mathrm{~m}^{3} / \mathrm{s}$. The liquid and gas stirrers were driven at constant speeds of 1.67 and $9.17 \mathrm{~s}^{-1}$, respectively. The duration of the experimental run was $43 \mathrm{~min}$. The absorption rate of $\mathrm{Cl}_{2}$ and the desorption rate of $\mathrm{CO}_{2}$ were determined by the same methods as used in the previous work. ${ }^{5)}$

\section{Results and Discussion}

\subsection{Prediction of physical properties}

When the dissolved $\mathrm{Cl}_{2}$ reacts with $\mathrm{NaHCO}_{3}$ in solution, an aqueous solution containing $\mathrm{HOCl}, \mathrm{NaCl}$ and $\mathrm{HCl}$ exists near the gas-liquid interface. The interfacial concentrations of $\mathrm{HOCl}, \mathrm{NaCl}$ and $\mathrm{HCl}$, $E_{i}, F_{i}$ and $J_{i}$ respectively, are given by Eqs. (13) to (15). Therefore, as the liquid-phase diffusivity and the physical solubility for each of the two gases and the equilibrium constant and the reaction rate constant of reaction (4), the values for this mixed solution should be used for the analysis of the experimental results. The effects of the presence of $\mathrm{HCl}$ on the liquid-phase diffusivity, physical solubility and equilibrium constant of reaction (4) were assumed to be negligible, since the interfacial concentration $J_{i}$ of $\mathrm{HCl}$ was very low (less than $8.4 \mathrm{~mol} / \mathrm{m}^{3}$ ).

The forward rate constant $k_{4}$ of reaction (4) at $25^{\circ} \mathrm{C}$ was taken to be equal to $15.4 \mathrm{~s}^{-1},{ }^{1)}$ and the equilibrium constant $K_{4}$ of reaction (4) at $25^{\circ} \mathrm{C}$ was taken as $3.94 \times 10^{2} \mathrm{~mol}^{2} / \mathrm{m}^{6}{ }^{2)}$ The effects of the ionic strength of the solution on these values were assumed to be negligible. The other physical properties of the present system were estimated by the same methods as used in the previous work. ${ }^{5)}$

\subsection{Comparison of experimental results with theory}

The measured desorption rate $N_{C}$ of $\mathrm{CO}_{2}$ from an aqueous $\mathrm{NaHCO}_{3}$ solution of $B_{f}=33.0 \mathrm{~mol} / \mathrm{m}^{3}$ was found to vary from $3.7 \times 10^{-4}$ to $3.5 \times 10^{-4} \mathrm{~mol} / \mathrm{m}^{2} \cdot \mathrm{s}$ as the bulk concentration $B_{0}$ of $\mathrm{NaHCO}_{3}$ in the solution decreased from 23.0 to $6.8 \mathrm{~mol} / \mathrm{m}^{3}$. These experimental data were in good agreement with the theoretical predictions from Eq. (16), the average deviation being $1.2 \%$. (The graph of $N_{C}$ vs. $B_{0}$ was omitted in this paper for brevity.) It should be noted that the $\mathrm{CO}_{2}$ desorption rate is independent of the $\mathrm{Cl}_{2}$ hydrolysis reaction, as mentioned above.

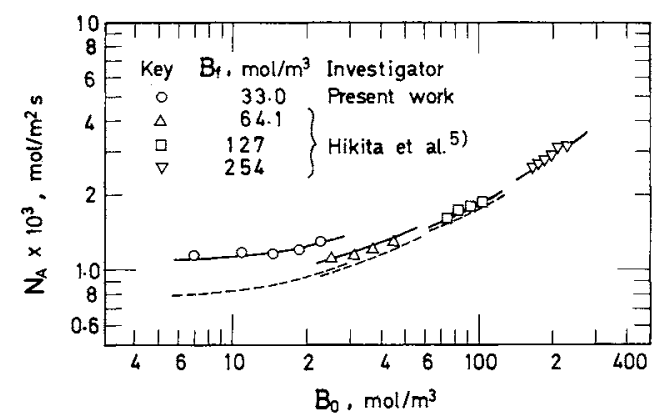

Fig. 2. Absorption rate of $\mathrm{Cl}_{2}$ into aqueous $\mathrm{NaHCO}_{3}$ solutions at $25^{\circ} \mathrm{C}$ : - , theoretical absorption rate which takes into account the effect of $\mathrm{Cl}_{2}$ hydrolysis reaction; - - - , theoretical absorption rate which assumes a negligible effect of $\mathrm{Cl}_{2}$ hydrolysis reaction.

Figure 2 shows the experimental results for the adsorption of $\mathrm{Cl}_{2}$ into an aqueous $\mathrm{NaHCO}_{3}$ solution of $B_{f}=33.0 \mathrm{~mol} / \mathrm{m}^{3}$ as a $\log -\log$ plot of the $\mathrm{Cl}_{2}$ absorption rate $N_{A}$ vs. the $\mathrm{NaHCO}_{3}$ bulk concentration $B_{0}$. In this figure, the experimental data for $\mathrm{NaHCO}_{3}$ solutions of $B_{f}=64.1,127$ and $254 \mathrm{~mol} / \mathrm{m}^{3}$ which were obtained in the previous work ${ }^{5)}$ are also shown. The solid lines represent the theoretical absorption rates which take into account the effect of the $\mathrm{Cl}_{2}$ hydrolysis reaction, and were calculated from Eqs. (7), (9) to (11), and (13) to (15). The dashed lines show the theoretical absorption rates which assume that the effect of the $\mathrm{Cl}_{2}$ hydrolysis reaction is negligible, and were calculated from Eqs. (7) and (17). Thus, the distance between the solid and dashed lines for each solution is a measure of the effect of the $\mathrm{Cl}_{2}$ hydrolysis reaction on the absorption rate. It can be seen in the figure that the solid lines for solutions of $B_{f}=33.0,64.1$ and $127 \mathrm{~mol} / \mathrm{m}^{3}$ lie about 34,15 and $3.0 \%$ above the dashed lines for the same solutions, and that for a solution of $B_{f}=254 \mathrm{~mol} / \mathrm{m}^{3}$ both the theoretical lines agree well within about $0.4 \%$. The measured absorption rates of $\mathrm{Cl}_{2}$ shown in Fig. 2 are in good agreement with the solid lines rather than the dashed lines, with an average deviation of $2.9 \%$, indicating that for $\mathrm{NaHCO}_{3}$ solutions of low concentrations the effect of the $\mathrm{Cl}_{2}$ hydrolysis reaction on the absorption rate cannot be neglected.

\section{Nomenclature}

A $=$ concentration of $\mathrm{Cl}_{2}$ in solution $\quad\left[\mathrm{mol} / \mathrm{m}^{3}\right]$

$=$ concentration of $\mathrm{HCO}_{3}{ }^{-}$ions in solution

$=$ concentration of $\mathrm{CO}_{2}$ in solution

$=$ liquid-phase diffusivity

= concentration of $\mathrm{HOCl}$ in solution

$=$ concentration of $\mathrm{Cl}^{-}$ions in solution

$=$ concentration of $\mathrm{OCl}^{-}$ions in solution

$\begin{array}{ll}J & =\text { concentration of } \mathrm{H}^{+} \text {ions in solution } \\ K_{4} & =\text { equilibrium constant of reaction (4) }\end{array}$

$k_{4}=$ forward rate constant of reaction (4) 


$\begin{array}{lll}N_{A} & =\text { absorption rate of } \mathrm{Cl}_{2} & {\left[\mathrm{~mol} / \mathrm{m}^{2} \cdot \mathrm{s}\right]} \\ N_{C} & =\text { desorption rate of } \mathrm{CO}_{2} & {\left[\mathrm{~mol} / \mathrm{m}^{2} \cdot \mathrm{s}\right]} \\ \beta_{A} & =\text { reaction factor for the desorption of } \mathrm{Cl}_{2} & {[-]} \\ \beta_{C} & =\text { reaction factor for the absorption of } \mathrm{CO}_{2} & {[-]} \\ \gamma & =\text { parameter defined by Eq. (11) }\end{array}$

$\langle$ Subscripts

$$
\begin{array}{ll}
A & =\mathrm{Cl}_{2} \\
B & =\mathrm{HCO}_{3}^{-} \text {ions } \\
C & =\mathrm{CO}_{2} \\
E & =\mathrm{HOCl} \\
F & =\mathrm{Cl}^{-} \text {ions } \\
f & =\text { initial concentration } \\
G & =\mathrm{OCl}^{-} \text {ions } \\
i & =\text { gas-liquid interface } \\
J & =\mathrm{H}^{+} \text {ions } \\
r & =\text { reaction plane } \\
0 & =\text { bulk of liquid } \\
1 & =\text { region } 1
\end{array}
$$

\section{Literature Cited}

1) Brian, P. L. T., J. E. Vivian and C. Piazza: Chem. Eng. Sci., 21, 551 (1966).

2) Connick, A. E. and Y. T. Chia: J. Am. Chem. Soc., 81, 1280 (1959).

3) Harned, H. S. and B. B. Owen: "The Physical Chemistry of Electrolytic Solutions," 3rd ed., p. 691, Reinhold, New York (1958).

4) Hikita, H., S. Asai, H. Ishikawa and Y. Saito: Chem. Eng. Sci., 30, 607 (1975).

5) Hikita, H., S. Asai and Y. Konishi: J. Chem. Eng. Japan, 16, 42 (1983).

6) Morris, J. C.: J. Phys. Chem., 70, 3798 (1966).

7) Pinsent, B. R. W., L. Pearson and F. J. W. Roughton: Trans. Faraday Soc., 52, 1512 (1956).

\section{EXTRACTION RATE OF PROPIONIC ACID WITH LONG-CHAIN ALKYLAMINE IN HORIZONTAL RECTANGULAR CHANNEL}

In this paper, the extraction rate of propionic acid with $n$-hexane solutions of Amberlite LA-2 (hereafter called LA-2) and of tri- $n$-octylamine (hereafter called TOA) in a horizontal rectangular channel are measured, and the results are interpreted by the interfacial reaction model proposed in the previous paper. ${ }^{5)}$

\section{Experimental Procedure}

Experimental apparatus and procedures are the same as those described previously. ${ }^{5}$ Flow rates of an aqueous and organic phases were equalized and varied from $0.3 \times 10^{-6} \mathrm{~m}^{3} / \mathrm{s}$ to $0.8 \times 10^{-6} \mathrm{~m}^{3} / \mathrm{s}$, in which range no ripples were observed at the interface.

\section{Results and Discussion}

Experimental results are shown in Figs. 1 and $\mathbf{2}$ where $\overline{S h}\left(=\left(\Delta C_{\mathrm{A}} \tilde{u}_{\mathrm{A}} h^{2} / C_{\mathrm{A} 0} D_{\mathrm{A}} x_{\mathrm{L}}\right)\right)$ is plotted against $\alpha \sqrt{\beta}\left(=\left(C_{\mathrm{A} 0} / C_{\mathrm{B} 0}\right) \sqrt{D_{\mathrm{A}} / D_{\mathrm{B}}}\right)$ at constant Graetz number, $G z\left(=\left(\bar{u}_{\mathrm{A}} h^{2} / D_{\mathrm{A}} x_{\mathrm{L}}\right)\right)=346$. Diffusion coefficients, $D_{\mathrm{A}}$ and $D_{\mathrm{B}}$, were estimated from an equation of Wilke et al., ${ }^{7}$ that is, $D_{\mathrm{A}}=0.9 \times 10^{-9} \mathrm{~m}^{2} / \mathrm{s}$ and $D_{\mathrm{B}}=1.4 \times$ $10^{-9} \mathrm{~m}^{2} / \mathrm{s}$ for LA-2 and $1.5 \times 10^{-9} \mathrm{~m}^{2} / \mathrm{s}$ for TOA.

It has been known that propionic acid (A) reacts with the amines (B) to form $\mathrm{A}_{n} \mathrm{~B}(n=1,2,3$ and 4)

\footnotetext{
Received January 7, 1983. Correspondence concerning this article should be addressed,
to Y. Kawano.
}

\author{
YOSHINOBU KAWANO AND KAZUHITO KUSANO \\ Department of Chemical Industry, Miyazaki Univ., Miyazaki 880
}

type species. In the range of $\alpha \sqrt{\beta}<10$, the concentration of $\mathrm{A}_{4} \mathrm{~B}$ species can be assumed to be negligibly small compared with others. ${ }^{4,6)}$ The reaction scheme can be assumed to be the same as that given in the extraction of acetic acid with the amines $\left.{ }^{5}\right)$ as shown in Fig. 3, ${ }^{*}$ where $k_{\mathrm{a} 01}^{\circ}, k_{\mathrm{s} n 1}^{\circ}$ and $k_{\mathrm{d} n 1}^{\circ}(n=1,2$ and 3 ) are the rate constants, and $K_{\mathrm{a} 01}, K_{\mathrm{sm} 1}$ and $K_{\mathrm{d} n 1}$ $(n=1,2$ and 3$)$ are the equilibrium constants.

When the reaction proceeds only at the interface, the fundamental equations and the boundary conditions can be derived as given in the previous paper. ${ }^{3,5)}$ The relations between $\overline{S h}$ and $\alpha \sqrt{\beta}$ are obtained by solving these equations.

Dotted lines in Figs. 1 and 2 are the calculated results $^{3)}$ assuming that $\mathrm{A}_{3} \mathrm{~B}$ type species are formed irreversibly and instantaneously at the interface. The broken lines in Figs. 1 and 2 are the calculated results assuming that all steps in Fig. 3 equilibrate instantaneously at the interface. The fact that most experimental $\overline{S h}$ values fall under the broken lines indicates that the extraction rate is affected by the

\footnotetext{
* Assuming that the amines (B) reacts with the acid (A) dissolved in the organic phase, the relation between $\overline{S h}$ and $\alpha \sqrt{\beta}$ can be calculated analytically, ${ }^{1)}$ and the value of $\overline{S h}$ should be independent of $\alpha \sqrt{\beta}$. It is assumed therefore that $B$ reacts with $A$ at the interface.
} 